EPJ Web of Conferences 44, 04008 (2013)

DOI: $10.1051 /$ epjconf/20134404008

C Owned by the authors, published by EDP Sciences, 2013

\title{
Erratum to: FL-LMTO investigation of the structural, electronic and agneticproperties of Heusler compounds Ru2CrZ (Ge, Sn, Si)
}

\section{Z. Aarizou, S. Bahlouli and M. Elchikh}

Laboratoire de Physique des Matériaux et des Fluides, Département de Physique, Université des Sciences et de la Technologie d'Oran-MB, BP. 1505, Oran El Mnaouer, Algeria

Original article:

EPJ Web of Conferences 44, 04002 (2013), DOI: 10.1051/epjconf/20134404002

We correct two errors in the original publication:

1. The title should be: First-principle calculations of the electronic structure and magnetism in antiferromagnetic full Heusler compounds $\mathrm{Ru}_{2} \mathrm{CrZ}$ (Ge, Sn, Si)

2. Table 3 on page 3, describing the calculated absolute local magnetic moment ( $\left.\mu_{\mathrm{B}}\right)$ of $\mathrm{Cr}$ and $\mathrm{Ru}$ atoms in $\mathrm{Ru}_{2} \mathrm{CrZ}$ compounds, should be:

\begin{tabular}{|c|c|c|}
\hline & $|M C r|$ & $|M R u|$ \\
\hline $\mathrm{Ru}_{2} \mathrm{CrSi}$ & 2.173 & 0.045 \\
\hline $\mathrm{Ru}_{2} \mathrm{CrGe}$ & 2.291 & 0.094 \\
\hline $\mathrm{Ru}_{2} \mathrm{CrSn}$ & 2.483 & 0.078 \\
\hline
\end{tabular}

